\title{
BIOMASSA AÉREA DE UMA FLORESTA OMBRÓFILA MISTA ALUVIAL NO MUNICÍPIO DE ARAUCÁRIA (PR)
}

\author{
Luis Gustavo Socher*, Carlos Vellozo Roderjan**, Franklin Galvão** \\ *Eng. Florestal, M.Sc., Companhia Paranaense de Energia, COPEL - luis.socher@copel.com \\ **Eng. Florestal, Dr., Depto. de Ciências Florestais, UFPR - roderjan@ufpr.br - fgalvao@ufpr.br \\ Recebido para publicação: 05/02/2007 - Aceito para publicação: 31/10/2007
}

\begin{abstract}
Resumo
Em uma área de Floresta Ombrófila Mista Aluvial adjacente ao rio Barigüi, no município de Araucária (PR), foi realizado um levantamento da biomassa aérea, sendo analisadas a vegetação arbórea (folhas, frutos e sementes, galhos finos, galhos grossos, epífitas vasculares e avasculares, madeira e casca), a regeneração com altura superior a 1,30 m (fuste, galhos grossos, galhos finos, folhas e epífitas vasculares e avasculares), a regeneração com altura inferior a 1,30 m (parte aérea e raízes), a vegetação herbácea (parte aérea e raízes) e a serapilheira. Foram medidas algumas variáveis dendrométricas dos indivíduos incluídos no estudo, além da obtenção do peso de matéria verde e coleta de amostras para determinação do peso de matéria seca. Como resultado geral, obteve-se uma biomassa aérea total de 195,51 t/ha, com a vegetação arbórea correspondendo a $86,88 \%$ desse valor, seguida da regeneração acima de $1,30 \mathrm{~m}$ de altura $(10,27 \%)$, da serapilheira $(2,23 \%)$, da regeneração abaixo de $1,30 \mathrm{~m}$ de altura $(0,39 \%)$ e da vegetação herbácea $(0,23 \%)$.

Palavras-chave: Biomassa aérea; floresta ciliar; floresta com araucária.
\end{abstract}

\section{Abstract}

Aerial biomass in a floodplain Forest at Araucaria, Parana State, South Brazil. The studied site is located at Araucária (PR), Brazil, in an area of floodplain forest, near to Barigui River. The aerial biomass was evaluated in this area, focusing on the arboreal vegetation (leaves, fruits, seeds, thin and thick branches, vascular and non-vascular epiphytes, wood and bark), the regenerated vegetation higher than $1.30 \mathrm{~m}$ (trunk, thin and thick twigs, leaves, vascular and non-vascular epiphytes), the regenerating vegetation lower than $1.30 \mathrm{~m}$ (aerial parts and roots), the herbaceous (aerial parts and roots) and litter. Some dendrometric variables of the studied materials were measured, the green weight and samples of the plants collected to measure the dry weight. As general results, dry aerial biomass of $195.5 \mathrm{t} / \mathrm{ha}$ was obtained with the arboreal vegetation correspond to $86.88 \%$ of this value, followed by the regenerating vegetation higher than $1.30 \mathrm{~m}(10.27 \%)$, the litter $(2.23 \%)$, the regenerating vegetation lower than 1.30 $\mathrm{m}(0.38 \%)$ and the herbaceous $(0.23 \%)$.

Keywords: Aerial biomass; riparian forest; araucaria forest.

\section{INTRODUÇ̃̃O}

As florestas ripárias, conhecidas como florestas de galeria ou ciliares, exercem importante função na estabilidade do regime hídrico das planícies sujeitas a inundações periódicas, decorrentes do transbordamento dos rios em ocasiões de máximas pluviométricas. A eliminação ou fragmentação dessas florestas é responsável por eventos desastrosos, comprometendo seriamente a segurança e a qualidade de vida de comunidades humanas indevidamente instaladas nesses ambientes, fato recorrente nos noticiários durante períodos chuvosos, em áreas mais densamente urbanizadas.

A partir da década de 90 do século passado, a pesquisa tem-se empenhado no melhor conhecimento dos ambientes ripários, através de estudos de natureza diversa. Com essa intenção, o presente artigo relata uma investigação inédita, trazendo à luz informações sobre os valores de biomassa vegetal aérea de uma floresta ripária, característica da região da Floresta Ombrófila Mista na sua formação Aluvial, no primeiro planalto do estado do Paraná. 
Para estudos confiáveis de biomassa, é necessária, ao menos numa primeira abordagem, a execução de uma amostragem destrutiva, na qual são analisados os diversos componentes da árvore, sendo que a separação e a especificação desses componentes variam de acordo com o tipo de floresta e os objetivos a serem alcançados.

Desde a década de 80 , vários estudos de biomassa têm sido elaborados em diversas partes do mundo, porém, na maioria de vezes, os resultados obtidos são extrapolados para ambientes com composição diferente da analisada, prejudicando sua utilização como base comparativa.

\section{MATERIAL E MÉTODO}

\section{Área de estudo}

A área estudada está localizada na porção centro-sul do primeiro planalto paranaense, no município de Araucária (Figura 1), a uma altitude média de 900 m s.n.m., tendo como coordenadas aproximadas $25^{\circ} 35^{\prime} 12^{\prime}$ ' $\mathrm{S}$ e $49^{\circ} 20^{\prime} 45^{\prime}, \mathrm{W}$.

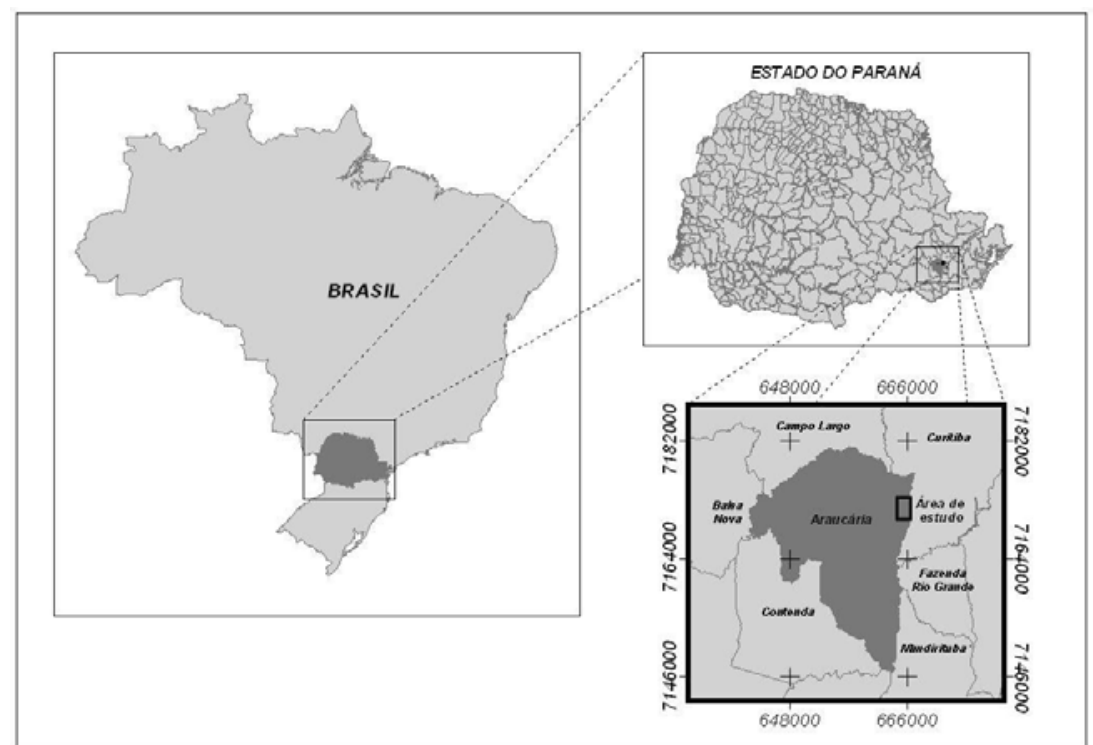

Figura 1. Localização da área de estudos no estado do Paraná, no município de Araucária.

Figure 1. Geographical location of the studied area in Parana State, municipality of Araucaria.

O clima da região é Cfb (Köppen), típico do Planalto Meridional brasileiro, com chuvas bem distribuídas ao longo do ano (1.400-1.600 mm/ano) e com inverno rigoroso (IAPAR, 2000). Segundo Barddal (2002), o local estudado é influenciado, mesmo que de forma amena, pela umidade e calor do oceano, do qual dista cerca de $100 \mathrm{~km}$. A temperatura média anual é de $16,5^{\circ} \mathrm{C}$, com mínimas podendo atingir valores negativos inferiores a $-5{ }^{\circ} \mathrm{C}$, e máximas superiores a $33{ }^{\circ} \mathrm{C}$ (FUNPAR, 2001).

A área analisada está estabelecida em uma planície, no reverso do dique marginal do rio Barigüi, possuindo solo de origem alúvio-coluvionar formado por sedimentos de fina granulometria denominado Gleissolo háplico (BARDDAL et al., 2004). Os solos dessa classe são permanente ou periodicamente saturados por água e geralmente desenvolvem-se em sedimentos recentes nas proximidades dos cursos d'água e em materiais alúvio-coluvionares sujeitos a condições de hidromorfia, sendo possível sua ocorrência em áreas planas de terraços fluviais, lacustres ou marinhos, em materiais residuais em áreas abaciadas e depressões ou, eventualmente, em áreas inclinadas sob influência do afloramento de água subterrânea (EMBRAPA, 1999).

O principal corpo d'água no local é o rio Barigüi, considerado um dos principais afluentes da margem direita no terço superior do rio Iguaçu. Nesse trecho, o rio teve seu curso retificado em meados da década de 60, por ação do Departamento Nacional de Obras de Saneamento, visando propiciar maior vazão e minimizar o efeito de enchentes (DNOS, 1979). O arroio Saldanha, pequeno tributário com pouco 
mais de 2,2 km de extensão em linha reta, atravessa a área de estudo em direção ao rio principal (FUNPAR, 2001; BARDDAL et al., 2004).

A vegetação, enquadrada pelo IBGE (1992) como Floresta Ombrófila Mista Aluvial, encontra-se em bom estado de conservação (apesar da grande modificação sofrida na área da refinaria, sobretudo nos interflúvios), mantendo, em grande parte, suas características originais. Contudo, é possível que, mesmo sem aparente interferência humana, tenha tido sua estrutura alterada após a modificação do curso e do leito do rio Barigüi e, conseqüentemente, das características hídricas locais (BARDDAL, 2002).

\section{Procedimento metodológico}

Devido à construção de uma usina termelétrica nas proximidades, uma das torres da linha de transmissão para o escoamento da energia produzida foi projetada em uma área da floresta anteriormente descrita, o que implicou a remoção da vegetação daquele local, após, evidentemente, liberação pelos órgãos ambientais. Salienta-se que se trata de área de preservação permanente definida pelo Código Florestal Brasileiro (Lei 4771/65) e posteriores alterações. Sendo assim, não foi possível atender aos critérios estatísticos quanto à intensidade amostral, pois a área passível de remoção da vegetação limitouse a $200 \mathrm{~m}^{2}$, suficiente para instalação de apenas duas parcelas de $100 \mathrm{~m}^{2}$ cada uma. Porém trata-se de oportunidade singular para um maior conhecimento desse ambiente.

Para o estudo de biomassa, utilizou-se a amostragem direta destrutiva conforme Andrae; Krapfenbauer (1976), que consiste em determinar a biomassa pelo corte e pesagem de todas as frações envolvidas dentro de uma determinada área, conforme detalhamento a seguir.

\section{Vegetação arbórea}

Foram incluídos nesse estrato todos os indivíduos com perímetro à altura do peito (PAP) igual ou superior a $15 \mathrm{~cm}$. Seguindo tal critério, foram delimitadas duas parcelas de $100 \mathrm{~m}^{2}$, onde 96 indivíduos foram abatidos, medidos e pesados. Os 12 indivíduos restantes em uma das parcelas, não avaliados por problemas operacionais, tiveram sua biomassa estimada após o ajuste de modelos matemáticos apropriados.

Cada árvore abatida foi identificada quanto à espécie botânica e, com auxílio de serras manuais e de tesouras de poda, obtiveram-se, de cada indivíduo, as frações folhas, frutos, sementes, galhos finos (menores que $1 \mathrm{~cm}$ de diâmetro), galhos grossos (maiores que $1 \mathrm{~cm}$ de diâmetro), epífitas vasculares, epífitas avasculares, madeira e casca. Essas frações foram pesadas em uma balança Micheletti, com capacidade máxima de $150 \mathrm{~kg}$ e precisão de $50 \mathrm{~g}$.

Para cada fração analisada, foi selecionada uma amostra de tamanho variável (mínimo de $10 \mathrm{~g}$ ), com o objetivo de determinar o percentual de umidade. Essa amostra foi pesada com balança de precisão de $0,5 \mathrm{~g}$ (balança J.B., carga máxima de $1.610 \mathrm{~g}$ ) e acondicionada em embalagem adequada para posteriormente ser levada à estufa de circulação forçada, a uma temperatura de $65^{\circ} \mathrm{C} \pm 5{ }^{\circ} \mathrm{C}$, até adquirir peso constante. O período de permanência dessa amostra na estufa variou de 48 horas a uma semana, dependendo da fração considerada.

Para determinação da biomassa da casca, foi coletada uma amostra do fuste a $1,30 \mathrm{~m}$ de altura, do qual foi retirada a casca, cujo percentual foi calculado em relação à madeira e generalizado para todo o indivíduo.

\section{Regeneração (maior que 1,30 m de altura)}

Nesse estrato, considerou-se como regeneração todos os indivíduos arbóreos com altura superior a 1,30 m que tinham o PAP inferior a $15 \mathrm{~cm}$. Sendo assim, dentro de cada uma das parcelas de $100 \mathrm{~m}^{2}$ foi instalada uma subparcela de $25 \mathrm{~m}^{2}$,para avaliação da biomassa da regeneração, sendo consideradas as seguintes frações: folhas, galhos finos, galhos grossos, fuste e epífitas vasculares e avasculares. O percentual de umidade foi determinado por meio da coleta de amostras, conforme descrito para a vegetação arbórea.

\section{Vegetação herbácea e regeneração (menor que 1,30 m de altura)}

Foram instaladas e medidas dez subparcelas de $1 \mathrm{~m}^{2}$ cada uma (cinco em cada parcela da vegetação arbórea), para avaliação da biomassa de herbáceas e de regeneração com altura inferior a 1,30 $\mathrm{m}$, considerando-se apenas duas frações: parte aérea e raízes.

Essas frações foram separadas e avaliadas quanto ao peso de matéria verde, sendo também coletadas amostras para a determinação do percentual de umidade. 
Também foi avaliada a quantidade de serapilheira existente, utilizando-se, para isso, cinco medições por parcela. Cada medição foi executada com auxílio de um gabarito circular de 50 centímetros de diâmetro, sendo pesado todo material incluído no seu interior, além da coleta de amostra para determinação da umidade.

Na figura 2, observam-se a disposição e a configuração das parcelas instaladas para a análise de biomassa dos diferentes estratos estudados.

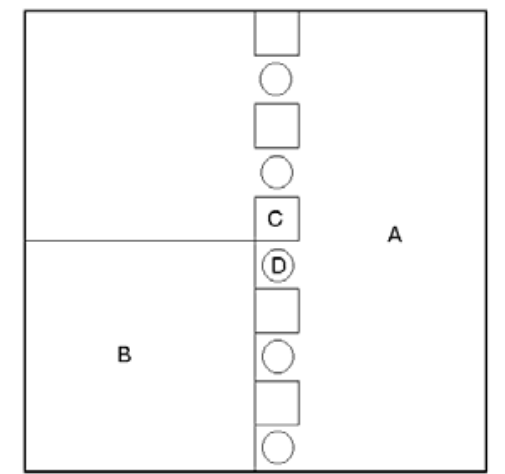

Figura 2. Croqui das parcelas para avaliação da biomassa aérea (A: arbórea $\left(100 \mathrm{~m}^{2}\right)$; B: regeneração > $1,30 \mathrm{~m}$ (uma subparcela de $25 \mathrm{~m}^{2}$ ); C: regeneração $<1,30 \mathrm{~m}$ e herbáceas (cinco subparcelas de $1 \mathrm{~m}^{2}$ ); D: serapilheira (cinco subparcelas com raio de $0,50 \mathrm{~m}$ )).

Figure 2. Lay out of plots for aerial biomass evaluation (A: arboreal vegetation $\left(100 \mathrm{~m}^{2}\right)$; B: regenerating vegetation higher than $1.30 \mathrm{~m}$ (one plot of $\left.25 \mathrm{~m}^{2}\right)$; C: regenerating vegetation lawer than $1.30 \mathrm{~m}$ and herbaceous (five plots of $1 \mathrm{~m}^{2}$ ); D: litter (five plots of $\left.0.7854 \mathrm{~m}^{2}\right)$ ).

De posse de todos os valores de peso de matéria seca, os mesmos foram organizados em planilhas, utilizando-se o software Excel for Windows ${ }^{\circledR}$ para os demais cálculos, sendo apresentados os resultados para a floresta como um todo, para cada estrato e para cada fração dentro dos estratos.

\section{RESULTADOS E DISCUSSÃO}

\section{Vegetação arbórea}

Os indivíduos arbóreos amostrados representam bem a vegetação típica de Floresta Ombrófila Mista Aluvial do primeiro planalto paranaense, onde, no rio Iguaçu e em seus principais tributários, predominam solos hidromórficos, sendo Sebastiania commersoniana (Euphorbiaceae) a espécie dominante (BUFREM, 1997; FUNPAR, 2001; FUNPAR, 2002; RODERJAN et al., 2002; PASDIORA, 2003; BARDDAL et al., 2004; CURCIO et al., 2007). Dos 108 indivíduos que serviram de base para o estudo de biomassa da vegetação arbórea, 64 são Sebastiania commersoniana (Baillon) L.B. Smith \& R.J. Downs, 12 são Myrceugenia glaucescens (Cambess.) D. Legrand \& Kausel. (Myrtaceae), sendo o complemento distribuído de maneira uniforme entre as espécies Myrciaria tenella (DC.) O. Berg, Myrcia laruotteana Cambess., Myrrhinium atropurpureum Schott., Blepharocalyx salicifolius (Kunth) O. Berg. (Myrtaceae), Schinus terebinthifolius Raddi, Lithraea brasiliensis March. (Anacardiaceae) e Xylosma pseudosalzmanii Sleumer (Flacourtiaceae). No conjunto, os indivíduos arbóreos amostrados representariam uma densidade absoluta de 5.400 indivíduos/hectare.

Os resultados obtidos mostram uma biomassa seca de aproximadamente $170 \mathrm{t} / \mathrm{ha}$, sendo que as porções que mais contribuíram para esse valor foram madeira $(52,84 \%)$, galhos grossos $(35,19 \%)$ e galhos finos $(5,12 \%)$. As porções que menos contribuíram para a biomassa total foram frutos e sementes, com $0,001 \%$, e outros (flores, botões etc.), com $0,003 \%$ (Tabela 1). Watzlawick et al. (2002), em trabalho realizado em um ambiente de Floresta Ombrófila Mista Montana, no município de General Carneiro, estado do Paraná, encontraram valores de 69,4 t/ha de biomassa aérea para um estágio inicial de sucessão, 168,8 t/ha em um estágio intermediário e 397,8 t/ha em estágio avançado, sendo que a contribuição da porção madeira variou entre 40 e $47 \%$. Dauber et al. (2000), em pesquisa nas florestas tropicais da Bolívia, citam que a biomassa aérea total do estrato arbóreo analisado variou de 97 a $171 \mathrm{t} / \mathrm{ha}$. Brown et 
al. (1989) mostraram que, na Ásia, foram obtidos valores que variam de $36 \mathrm{t} / \mathrm{ha}$ em uma floresta secundária em estágio inicial até 382 t/ha em uma floresta montana num estágio avançado. Alguns outros trabalhos foram realizados no país, porém nenhum deles especificamente em Floresta Ombrófila Mista Aluvial, havendo também grande variação na metodologia utilizada, impossibilitando a apresentação de outros dados comparativos.

Tabela 1. Biomassa aérea dos indivíduos arbóreos e as frações analisadas.

Table 1. Aerial biomass of the arboreal individuals from the analyzed compartments.

\begin{tabular}{lrrr}
\hline \multirow{2}{*}{ Frações } & \multicolumn{3}{c}{ Biomassa } \\
\cline { 2 - 4 } & $\mathbf{k g} / \mathbf{2 0 0} \mathbf{~ m}^{\mathbf{2}}$ & \multicolumn{1}{c}{$\mathbf{~ g} / \mathbf{h a}$} & $\mathbf{\% ~ d o ~ t o t a l}$ \\
\hline Madeira & $1.794,95$ & $89.747,55$ & 52,839 \\
Galhos grossos & $1.195,29$ & $59.764,55$ & 35,186 \\
Galhos finos & 174,09 & $8.704,66$ & 5,125 \\
Casca & 148,11 & $7.405,52$ & 4,360 \\
Folhas & 72,00 & $3.600,14$ & 2,120 \\
Epífitas vasculares & 9,43 & 471,59 & 0,278 \\
Epífitas avasculares & 3,03 & 151,48 & 0,089 \\
Frutos e sementes & 0,03 & 1,72 & 0,001 \\
Outros & 0,10 & 4,83 & 0,003 \\
Total & $3.397,04$ & $169.852,04$ & 100,00 \\
\hline
\end{tabular}

Alguns valores aqui obtidos raramente são apresentados em outros trabalhos do gênero, como é o caso da contribuição do material epifítico na biomassa total do ambiente - cerca de $623,1 \mathrm{~kg} / \mathrm{ha}$, sendo $471,6 \mathrm{~kg} / \mathrm{ha}$ de epífitas vasculares e $151,5 \mathrm{~kg} / \mathrm{ha}$ de epífitas avasculares.

Outras duas considerações devem ser feitas. A primeira quanto à fração casca, que teve sua biomassa calculada por meio de uma pequena amostra do fuste, não se levando em consideração as variações de espessura de casca que ocorrem ao longo do mesmo, obtendo-se um valor de 7,4 t/ha, que representa $4,36 \%$ da biomassa total. A segunda diz respeito às folhas, devido ao fato de a espécie mais importante da comunidade, Sebastiania commersoniana, ser decídua, perdendo totalmente suas folhas em determinada época do ano. Como a amostragem foi distribuída durante alguns meses (abril a agosto), alguns indivíduos foram medidos antes e outros depois da queda das folhas. Porém, isso não invalida os resultados obtidos, apenas justifica a pequena contribuição dessa fração (3,6 t/ha, representando $2,12 \%$ do total) na biomassa aérea da floresta.

\section{Regeneração (maior que 1,30 metro de altura)}

$\mathrm{Na}$ área amostrada $\left(50 \mathrm{~m}^{2}\right)$, foram encontrados 73 indivíduos com altura superior a 1,30 m e PAP inferior a $15 \mathrm{~cm}$, o que representa uma densidade absoluta de 14.600 indivíduos/hectare. A biomassa aérea total para esse estrato foi de aproximadamente 20,08 t/ha, sendo o fuste, com 70,38\%, a fração que mais contribuiu para esse valor (Tabela 2).

A contribuição relativa do fuste (madeira + casca) na biomassa total é muito superior ao obtido com a vegetação arbórea $(57,20 \%)$, pois existe uma diminuição da quantidade de galhos, resultado do investimento da planta em alongar o fuste para atingir os estratos intermediário e superior da floresta, onde encontrará maior disponibilidade de luz, favorecendo o seu estabelecimento na comunidade. Esse fato é reforçado pela análise da biomassa dos galhos, que, diferindo do ocorrido na vegetação arbórea, apresentou valores semelhantes quanto à biomassa seca dos galhos grossos (2,90 t/ha, ou seja, 14,47\% do total) e galhos finos (2,25 t/ha, representando $11,18 \%$ do total). Isso ocorre devido ao menor porte dos indivíduos, entre os quais são raros galhos com diâmetro superior a $1,0 \mathrm{~cm}$.

\section{Vegetação herbácea e regeneração (menor que 1,30 metro de altura)}

Nesse estrato, foram amostrados apenas $10 \mathrm{~m}^{2}$ (dez parcelas de $1 \mathrm{~m}^{2}$ cada uma), sendo encontrados 45 indivíduos em regeneração, o que representa uma densidade absoluta de 45.000 indivíduos/hectare, além da vegetação herbácea, que não foi analisada quanto à densidade, apenas quanto à biomassa.

Na tabela 3, tem-se uma síntese dos resultados obtidos, indicando que, quanto à regeneração menor que $1,30 \mathrm{~m}$ de altura, foi verificada uma biomassa total de $758,44 \mathrm{~kg} / \mathrm{ha}$, sendo que $75,72 \%$ desse valor estão 
concentrados na parte aérea e $24,28 \%$ nas raízes. A vegetação herbácea totalizou um peso de matéria seca de $448,55 \mathrm{~kg} / \mathrm{ha}$, e o valor total desse estrato (regeneração + herbáceas) foi de 1.206,99 kg/ha.

Tabela 2. Biomassa da regeneração (maior que $1,30 \mathrm{~m}$ de altura).

Table 2. Biomass of regeneration (higher than $1.30 \mathrm{~m}$ height).

\begin{tabular}{lrrr}
\hline \multirow{2}{*}{ Fração } & \multicolumn{3}{c}{ Biomassa } \\
\cline { 2 - 4 } & $\mathbf{k g} / \mathbf{5 0} \mathbf{~ m}^{\mathbf{2}}$ & $\mathbf{~ k g} / \mathbf{h a}$ & $\mathbf{\%}$ \\
\hline Fuste & 70,67 & $14.133,11$ & 70,38 \\
Galhos grossos & 14,53 & $2.905,80$ & 14,47 \\
Galhos finos & 11,23 & $2.245,86$ & 11,18 \\
Folhas & 3,89 & 778,47 & 3,88 \\
Epífitas vasculares & 0,08 & 16,04 & 0,08 \\
Epífitas avasculares & 0,02 & 3,074 & 0,02 \\
\hline Total & 100,41 & $20.082,35$ & 100,00 \\
\hline
\end{tabular}

Tabela 3. Biomassa da regeneração (menor que $1,30 \mathrm{~m}$ de altura) e herbáceas.

Table 3. Biomass of regeneration (lower than $1.30 \mathrm{~m}$ height) and herbaceous.

\begin{tabular}{lccc}
\hline \multirow{2}{*}{ Fração } & \multicolumn{3}{c}{ Biomassa } \\
\cline { 2 - 4 } & $\mathbf{k g} / \mathbf{1 0} \mathbf{~ m}^{\mathbf{2}}$ & $\mathbf{k g} / \mathbf{h a}$ & $\mathbf{\%}$ \\
\hline $\begin{array}{c}\text { Regeneração }<1,30 \mathrm{~m} \\
\text { Parte aérea }\end{array}$ & 0,574 & 574,32 & 75,72 \\
Raízes & 0,184 & 184,12 & 24,28 \\
Subtotal & 0,758 & 758,44 & 100,00 \\
Herbáceas & 0,449 & 448,55 & \\
\hline \multicolumn{2}{l}{ Total } & 1,207 & $1.206,99$ \\
\hline
\end{tabular}

Devido a dificuldades operacionais, as raízes foram analisadas somente nesse estrato, em face de tratar-se de indivíduos de menor porte e com menor quantidade de raízes, facilitando sua retirada.

\section{Serapilheira}

$\mathrm{Na}$ análise da serapilheira, foi obtida uma biomassa seca de $0,8569 \mathrm{~kg}$ para uma área amostrada de $1,9635 \mathrm{~m}^{2}$ (10 parcelas circulares com diâmetro de $0,50 \mathrm{~m}$ cada uma), o que corresponde a 4.364,16 $\mathrm{kg} / \mathrm{hectare}$.

O valor encontrado é inferior ao obtido por Watzlawick et al. (2002) no município de General Carneiro, Paraná, para uma Floresta Ombrófila Mista Montana, cujo valor médio foi de $8.030 \mathrm{~kg} / \mathrm{ha} \mathrm{nos}$ três estágios sucessionais. Portes (2000), em pesquisa realizada na Floresta Ombrófila Densa Altomontana e com base em informações mensais obtidas durante dois anos e meio, estimou a produção média anual de serapilheira em 4,5 t/ha/ano. Souza (2003), em trabalho realizado em Floresta Ombrófila Mista Aluvial, numa área próxima à desta pesquisa, efetuou um acompanhamento mensal da deposição de serapilheira e obteve como resultado um valor de $6.854,30 \mathrm{~kg} / \mathrm{ha} / \mathrm{ano}$, com maior deposição nos meses de inverno e menor nos meses de verão.

Ressalta-se que o valor encontrado nessa pesquisa se reporta ao estoque de serapilheira no momento da amostragem, diferindo dos resultados expostos por Souza (2003), que acompanhou a deposição de serapilheira durante todos os meses do ano.

Deve-se salientar que a época de coleta dos dados pode influenciar muito nos resultados obtidos para esse estrato, em função da remoção da serapilheira por cheias ocasionais ou pela decidualidade de uma das espécies, Sebastiania commersoniana, cuja densidade é superior a $60 \%$ nessa comunidade.

\section{Biomassa aérea total}

$\mathrm{Na}$ tabela 4, encontra-se a contribuição de cada estrato na biomassa aérea total da floresta estudada. A vegetação arbórea é a que apresenta a maior biomassa, com $86,88 \%$ do total. O sub-bosque (regeneração + herbáceas) apresentou uma biomassa de $21.289 \mathrm{~kg} / \mathrm{ha}$, valor semelhante ao encontrado por Watzlawick et al. (2002), que obtiveram uma média de $21.810 \mathrm{~kg} / \mathrm{ha}$ nos três diferentes estágios de regeneração (inicial, intermediário e avançado). 
Tabela 4. Valores de biomassa para os diferentes estratos estudados.

Table 4. Biomass values for the different studied strata.

\begin{tabular}{lrr}
\hline \multirow{2}{*}{ Estrato } & \multicolumn{2}{c}{ Biomassa } \\
\cline { 2 - 3 } & \multicolumn{1}{c}{$\mathbf{~ k g / h a}$} & \multicolumn{1}{c}{$\%$} \\
\hline Vegetação arbórea & $169.852,04$ & 86,88 \\
Regeneração $\geq 1,30$ m altura & $20.082,35$ & 10,27 \\
Regeneração $<1,30$ m altura & 758,44 & 0,39 \\
Herbáceas & 448,55 & 0,23 \\
Serapilheira & $4.364,16$ & 2,23 \\
\hline Total & $195.505,54$ & 100,00 \\
\hline
\end{tabular}

\section{CONCLUSÕES E RECOMENDAÇÕES}

As pesquisas relacionadas à biomassa florestal contemplam muito mais o aspecto econômico do que ecológico da mesma, refletindo em uma predominância de estudos com espécies e/ou tipologias que possuam valor comercial. Resultado disso é que inexistem outros trabalhos em Floresta Ombrófila Mista Aluvial que poderiam, inclusive, subsidiar decisões relativas à obtenção de créditos de carbono para recuperação de áreas de preservação permanente degradadas.

Apesar de essa tipologia florestal apresentar, quando em solos hidromórficos, uma riqueza de espécies inferior a outras, sua importância é tão significativa quanto, além de possuir uma biomassa com valores próximos a algumas pesquisas realizadas em florestas tropicais (estágios iniciais e médios de regeneração).

Existe uma crescente necessidade de estudos visando a conservação e recuperação dos ambientes ripários, contribuindo assim para a melhoria da qualidade de vida de toda a população, aumentando a vida útil dos mananciais de abastecimento de água e das usinas hidrelétricas e propiciando então benefícios econômicos, sociais e ambientais, ou seja, atingindo as metas de sustentabilidade tão difundidas mundialmente.

O conhecimento da contribuição do material epifítico deve ser incluído em futuros levantamentos, visto que se trata de um compartimento importante na composição do ecossistema, apesar de representar uma fração bastante pequena do total de biomassa. Também é relevante a execução de estudos que contemplem a biomassa de raízes, os quais despendem muito tempo e apresentam custos elevados, mas podem produzir resultados até agora pouco conhecidos.

Outras análises em locais com composição florística diferente da encontrada neste estudo devem ser efetuadas, ampliando a rede de dados nessa tipologia florestal.

\section{REFERÊNCIAS}

ANDRAE, F.; KRAPFENBAUER, A. Estudo da situação de biomassa e nutrientes de um reflorestamento de quatro anos com Eucalyptus saligna Smith em Santa Maria, RS. In: Pesquisas Austro-brasileiras 1973-1982 sobre Araucaria angustifolia, Podocarpus lambertii e Eucalyptus saligna. Viena: Universitaet fuer Bodenkultur, 1982. $112 \mathrm{p}$.

BARDDAL, M. L. Aspectos florísticos e fitossociológicos do componente arbóreo-arbustivo de uma floresta ombrófila mista aluvial - Araucária/PR. 90 f. Dissertação (Mestrado em Ciências Florestais) Setor de Ciências Agrárias, Universidade Federal do Paraná, Curitiba, 2002.

BARDDAL, M. L.; RODERJAN, C. V.; GALVÃO, F.; CURCIO, G. R. Caracterização florística e fitossociológica de um trecho sazonalmente inundável de floresta aluvial, em Araucária, PR. Ciência Florestal, Santa Maria, v. 14, n. 2, p. 37-50, 2004.

BRASIL. Departamento Nacional de Obras e Saneamento (DNOS). Rio Barigui: canalização e regularização. Curitiba, 1979.

BROWN, S.; LUGO, A. E.; GILLESPIE, A. J. R.; Biomass estimation methods for tropical forests with applications to forest inventory data. Forest Science, Lawrence, v. 35, n. 4, p. 881-902, 1989. 
BUFREN, A. M. Caracterização fitossociológica de um remanescente da floresta ripária do rio Pequeno, São José dos Pinhais - PR. 87 f. Dissertação (Mestrado em Botânica) - Setor de Ciências Biológicas, Universidade Federal do Paraná, Curitiba, 1997.

CURCIO, G. R.; GALVÃO, F.; BONNET, A.; BARDDAL, M. L., DEDECEK, R. A. A floresta fluvial em dois compartimentos do rio Iguaçu, Paraná, Brasil. Floresta, Curitiba, v. 37, n. 2, p. 125-147, 2007.

DAUBER, E.; TERÁN, J.; GUZMÁN, R. Estimaciones de biomassa y carbono en bosques naturales de Bolivia. Santa Cruz de la Sierra: Superintendencia Forestal, 2000. 32 p.

EMBRAPA. Centro Nacional de Pesquisa de Solos. Sistema brasileiro de classificação de solos. Brasília, DF: EMBRAPA. Serviço de Produção da Informação, 1999. 412 p.

FUNPAR - Fundação da Universidade Federal do Paraná para o Desenvolvimento da Ciência, da Tecnologia e da Cultura. Diagnóstico e monitoramento da cobertura vegetal da área de influência direta e indireta do vazamento de óleo da refinaria Presidente Getúlio Vargas - REPAR, Araucária / PR: Fase I - Diagnóstico. Curitiba, 2001, 82 p.

FUNPAR - Fundação da Universidade Federal do Paraná para o Desenvolvimento da Ciência, da Tecnologia e da Cultura. Diagnóstico e monitoramento da cobertura vegetal da área de influência direta e indireta do vazamento de óleo da refinaria Presidente Getúlio Vargas - REPAR, Araucária / PR: Fase II - Diagnóstico. Curitiba, 2002, 67 p.

IAPAR - Fundação Instituto Agronômico do Paraná. Cartas climáticas do Paraná. Londrina, 2000. 1 CD-ROM. Versão 1.0. 2000.

IBGE - Instituto Brasileiro de Geografia e Estatística. Manual técnico da vegetação brasileira. Rio de Janeiro: 1992.92 p. (Manuais Técnicos em Geociências, n.1).

PASDIORA, A. L. Florística e fitossociologia de um trecho de floresta ripária em dois compartimentos ambientais no rio Iguaçu, Paraná, Brasil. 48 f. Dissertação (Mestrado em Ciências Florestais) - Setor de Ciências Agrárias, Universidade Federal do Paraná, Curitiba, 2003.

PORTES, M. C. G. de O. Deposição de serapilheira foliar em Floresta Ombrófila Densa Altomontana, morro do Anhangava, serra da Baitaca, Quatro Barras, PR. 90 f. Dissertação (Mestrado em Ciências Florestais) - Setor de Ciências Agrárias, Universidade Federal do Paraná, Curitiba, 2000.

RODERJAN, C. V.; GALVÃO, F.; KUNIYOSHI, Y. S.; HATSCHBACH, G. G. As unidades fitogeográficas do estado do Paraná, Brasil. Revista Ciência \& Ambiente, Santa Maria, n. 24. 2002.

SOUZA, S. G. A. Produção e decomposição de serapilheira relacionado com variáveis metereológicas e fitossociológicas em uma Floresta Ombrófila Mista Aluvial, rio Barigüi, Araucária-PR. 127 f. Tese (Doutorado em Ciências Florestais) - Setor de Ciências Agrárias, Universidade Federal do Paraná, Curitiba, 2003.

WATZLAWICK, L. F.; KIRCHNER, F. F.; SANQUETTA, C. R; SCHUMACHER, M. V. Fixação de carbono em floresta ombrófila mista em diferentes estágios de regeneração. In: SANQUETTA, C. R.; WATZLAWICK, L. F.; BALBINOT, R.; ZILIOTTO, M. A. B.; GOMES, F. S. As florestas e o carbono. Curitiba 2002. p.153-173. 